\title{
Knowledge of Primary Care Physicians on Lysosomal Storage Disorders
}

\author{
๑ Engin Köse1, ๑ Selda Bülbül2, ๑ Nur Arslan³ \\ ${ }^{1}$ Behçet Uz Children Research and Training Hospital, Clinic of Pediatric Pediatric Metabolism and Nutrition, İzmir, Turkey \\ ${ }^{2}$ Kırıkkale University Faculty of Medicine, Department of Pediatric Pediatric Metabolism and Nutrition, İzmir, Turkey \\ ${ }^{3}$ Dokuz Eylül University Faculty of Medicine, Department of Pediatric Pediatric Metabolism and Nutrition, İzmir, Turkey
}

\begin{abstract}
Aim: Since patients with lysosomal storage disorders (LSDs) often apply to primary care physicians initially, these doctors play a crucial role in the early diagnosis of LSDs. In this study, we aimed to determine the knowledge and awareness of primary care physicians regarding LSDs.

Materials and Methods: We conducted a survey between January 2016 and April 2016 among primary care physicians from various regions of Turkey. Invitation e-mail was randomly sent to the individual e-mail address of each physician for a web-based survey. The questionnaire globally consisted of three sections with a total of 30 questions. In the first part of the survey, demographic characteristics of physicians (age, gender, career information) were recorded. The second section consisted of questions on LSDs for the evaluation of knowledge among physicians. In the third section of survey, questions were about the reasons of insufficient knowledge on LSDs and possible solutions to raise awareness.

Results: A total of 261 primary care physicians [109 females (41.8\%), mean age $40.1 \pm 8.8$ years] were enrolled in the study. The mean working time was $14.9 \pm 8.6$ years. Among the participants, $75.8 \%$ and $88.8 \%$ stated that they had never encountered an LSD patient before and never considered LSDs as a differential diagnosis for any patient, respectively. Fifteen percent of physicians stated that they had no idea about the clinical findings and symptoms of LSD. Another $26.2 \%$ of the participants stated that LSD is screened during the neonatal screening program in Turkey. Mean "total knowledge score" of the physicians was $13.47 \pm 5.85$ points [median=15.0 (10.5-18.0)] out of 25 . Six (2.3\%) primary care physicians had a total score of " 0 ". Only 1 of them scored " 25 " points.

Conclusion: Knowledge of primary care physicians on LSDs is not satisfactory in Turkey. Undergraduate medical education and postgraduate educations play a key role to raise awareness.
\end{abstract}

Keywords: Awareness, primary care physicians, lysosomal storage diseases, survey

\section{Introduction}

The lysosome is an intracellular organelle essential for the biochemical breakdown of several molecules such as oligosaccharides, glycosaminoglycans, sphingolipids and other lipids. Defects in lysosomal metabolism lead to accumulation of substrates and result in variable symptoms and findings collectively termed as lysosomal storage disorders (LSDs) which consist of over 40 inherited conditions (1). Age of onset, severity of symptoms and course of progression in LSDs vary from person to person due to the genetic defect affecting enzyme activity. These factors, and typically the absence of evidence at birth make the diagnosis difficult. Therefore, patients with LSD are often misdiagnosed 
and may spend years without knowing what they actually suffer from (2). On the other hand, the development and continual improvement of therapies such as hematopoietic stem cell transplantation (HSCT), enzyme replacement therapy (ERT) and substrate reduction therapy (SRT) for select LSDs make early diagnosis important. Therapeutic outcomes with ERT are generally more satisfactory in the early stages of these disorders (3). However, these disorders are usually not well recognized by physicians and diagnoses are often delayed. As most of the LSD patients present their symptoms first to primary care physicians, these doctors have a crucial role in the diagnosis of LSDs, in making appropriate referrals and coordinating other care support (4).

A literature review revealed insufficient data on LSD awareness levels among primary care physicians. Thus, we aimed to plan a study not only to evaluate awareness on LSDs, but also to determine the problems and expectations of primary care physicians regarding the diagnosis as well as the management of these rare disorders.

\section{Materials and Methods}

This study was conducted between January 2016 and April 2016. Primary care physicians from various regions of Turkey participated in the study. An invitation e-mail was randomly sent to the individual e-mail address of each participant. Google Forms (Google Inc., CA, USA) was used to create this web-based survey, invitation e-mails and data collection to ensure privacy. No consent was obtained.

\section{The Questionnaire}

The questionnaire globally consisted of three sections with a total of 30 questions (Table I). In the first part of the survey, demographic characteristics of physicians (age, gender, career information) were recorded.

The second section consisted of questions on LSDs for the evaluation of knowledge among physicians. For the objective evaluation of the participants, we scored the answers of the 15 questions on LSDs in this part of survey. The first part of the questions was to write down the names of three LSDs (1 point each), the estimated prevalence of LSDs (correct answer was 1 point), the pathogenesis of LSDs

\begin{tabular}{|c|c|c|}
\hline 1. & Age & \\
\hline 2. & Gender & $M / F$ \\
\hline 3. & How long have you been working as a medical doctor? & \\
\hline 4. & How long have you been working as a family doctor? & \\
\hline 5. & Which city are you working in? & \\
\hline 6. & Have you worked in any metabolic disease clinic before? & $\mathrm{Y} / \mathrm{N}$ \\
\hline 7. & Do you know someone with a metabolic disease? & $\mathrm{Y} / \mathrm{N}$ \\
\hline 8. & If yes, what is the diagnosis? & \\
\hline 9. & What is your level of knowledge regarding lysosomal storage diseases? & 1- No idea to, 10- It is my specialty \\
\hline 10. & Where did you learn about lysosomal storage diseases? & $\begin{array}{l}\text { *Medical education } \\
\text { *During my internship } \\
\text { *Preparation for TUS exam } \\
\text { *In the clinic } \\
\text { *My personal studies } \\
\text { *Following national magazines } \\
\text { *In congress } \\
\text { *I have no information regarding lysosomal storage } \\
\text { disease } \\
\text { *Other }\end{array}$ \\
\hline 11. & Do you know any lysosomal storage disease? & $\mathrm{Y} / \mathrm{N}$ \\
\hline 12. & If yes, can you please write down three of them? & \\
\hline 13. & Have you ever seen a patient with a lysosomal storage disease? & $\mathrm{Y} / \mathrm{N}$ \\
\hline 14. & $\begin{array}{l}\text { Do you believe that there was a patient who might have had a lysosomal storage } \\
\text { disease in your past career? }\end{array}$ & $\mathrm{Y} / \mathrm{N}$ \\
\hline 15. & What do you think about the incidence rate of lysosomal storage diseases? & \\
\hline 16. & How many lysosomal storage diseases do you think there are? & \\
\hline
\end{tabular}




\begin{tabular}{|c|c|c|}
\hline 17. & $\begin{array}{l}\text { Which one of the given might be true for the pathogenesis of lysosomal storage } \\
\text { diseases? }\end{array}$ & $\begin{array}{l}\text { *Number of lysosomes contained in a cell are high } \\
\text { from birth } \\
{ }^{*} \text { Decrease in enzymes within lysosomes based on } \\
\text { quantity or functionality from birth } \\
\text { *Dysfunctionality of lysosomes contained in cells } \\
\text { due to aging } \\
{ }^{*} \text { No idea } \\
{ }^{*} \text { Other }\end{array}$ \\
\hline 18. & Can genetic mutations cause lysosomal storage diseases? & $\mathrm{Y} / \mathrm{N}$ \\
\hline 19. & Does consanguineous marriage increase the risk of lysosomal storage diseases? & Y/N/No idea \\
\hline 20. & $\begin{array}{l}\text { Is Turkey, one of the countries where lysosomal storage diseases are observed the } \\
\text { most? }\end{array}$ & $\mathrm{Y} / \mathrm{N}$ \\
\hline 21. & $\begin{array}{l}\text { Which one of the given findings can be observed in lysosomal storage disease } \\
\text { patients? }\end{array}$ & $\begin{array}{l}\text { *Growth and developmental delay } \\
\text { *Mental retardation } \\
{ }^{*} \text { Coarse facies } \\
\text { *Hepatomegaly } \\
\text { *Splenomegaly } \\
{ }^{*} \text { Cataract and retinal findings } \\
\text { *Bone deformities } \\
\text { *Cardiomyopathy } \\
\text { *Seizure } \\
\text { *Abnormal renal function test } \\
\text { *No idea }\end{array}$ \\
\hline 22. & Can clinical findings of lysosomal storage disease be observed from birth? & Y/N/No idea \\
\hline 23. & Is it possible to prevent sequalae of lysosomal storage disease? & Y/N/No idea \\
\hline 24. & Do any of the lysosomal storage diseases have special treatments? & Y/N/No idea \\
\hline 25. & $\begin{array}{l}\text { Does a patient oriented diet have an important role in treating lysosomal storage } \\
\text { diseases? }\end{array}$ & Y/N/No idea \\
\hline 26. & Is there an enzyme replacement treatment approach in lysosomal storage diseases? & Y/N/No idea \\
\hline 27. & $\begin{array}{l}\text { Is there any lysosomal storage disease included in the newborn screening program } \\
\text { in Turkey? }\end{array}$ & Y/N/No idea \\
\hline 28. & $\begin{array}{l}\text { Given some patients with diagnosed lysosomal storage diseases. After scanning } \\
\text { these patients, would you reconsider your previous patients with lysosomal storage } \\
\text { diseases? } \\
\text { Male } 25 \text { with Isolated splenomegaly and no other findings / Female child } 7 \text { with } \\
\text { attention deficit and hyperactivity syndrome / Female } 40 \text { with isolated left ventricle } \\
\text { hypertrophy / Male } 28 \text { with isolated proteinuria and kidney tests in norms / } \\
\text { Female } 42 \text { with stroke attack without hypertension or hyperlipidemia / Female } 30 \\
\text { with petechia like angiokeratomas / Female } 21 \text { with stomach ache, diarrhea and } \\
\text { diagnosed irritable bowel syndrome since puberty }\end{array}$ & $\mathrm{Y} / \mathrm{N}$ \\
\hline 29. & $\begin{array}{l}\text { Ten cm of splenomegaly is observed on a } 16 \text {-year-old patient submitting the } \\
\text { complaint of nose bleeding. Patient has thrombocytopenia and leukopenia in } \\
\text { laboratory findings and bone marrow aspiration shows foam cells. } \\
\text { What is the most probable diagnosis for this patient? }\end{array}$ & \\
\hline 30. & $\begin{array}{l}\text { If you think your level of knowledge regarding lysosomal storage diseases is lower } \\
\text { than } 5 \text {, what would be the reason(s)? }\end{array}$ & $\begin{array}{l}\text { *Forgetting knowledge due to the rarity of these } \\
\text { diseases } \\
\text { *Insufficient undergraduate medical education } \\
\text { *Inadequate attention to LSDs in congress } \\
\text { *Insufficient literature on LSDs published in Turkish } \\
{ }^{*} \text { Other }\end{array}$ \\
\hline
\end{tabular}

LSD: Lysosomal storage disorders 
(correct answer was 1 point), the role of consanguinity and mutations, and the status of Turkey in the world in terms of the frequency of LSDs (each correct answer was 1 point). In the second part, common clinical findings of patients with LSD (growth and developmental delay, mental retardation, coarse facies, hepatomegaly, splenomegaly, seizure, skeletal abnormalities, cardiomyopathy, renal dysfunction, eye findings, (Table II) were listed in one question and physicians were asked to click on the symptoms that may be seen in LSD patients. This question and the following 6 questions were about clinical findings, symptomatology, diagnosis and treatment modalities of LSDs (in this section, correct answers were equivalent to 16 points in total). In the remaining question, clinical and laboratory findings of a hypothetical adolescent patient with Gaucher's Disease were described and the physicians were asked to write the true possible diagnosis (1 point). The total score of this section was 25 points.

In the third section of this survey, questions were about the reasons of insufficient knowledge on LSDs and possible solutions to raise awareness. The study protocol was designed in compliance with the 1964 Declaration of Helsinki. The study was approved by the Ethics Committee of Dokuz Eylül University Hospital (approval number: 2016/03-14).

\section{Statistical Analysis}

Data were recorded with the Statistical Package for Social Sciences version 15.0. Continuous and categorical variables were reported as mean \pm standard deviation [median (25-75 percentiles)] and number (\%), respectively.

Table II. Knowledge on different clinical findings of LSD patients among primary care physicians (\%)

\begin{tabular}{|l|l|}
\hline Clinical findings & $\mathbf{n}(\%)$ \\
\hline Growth and developmental delay & $203(78.1)$ \\
\hline Mental retardation & $170(65.4)$ \\
\hline Coarse facies & $160(61.5)$ \\
\hline Hepatomegaly & $160(61.5)$ \\
\hline Splenomegaly & $151(58.1)$ \\
\hline Cataract and retinal findings & $139(53.5)$ \\
\hline Bone deformities & $136(52.3)$ \\
\hline Cardiomyopathy & $118(45.4)$ \\
\hline Seizure & $115(44.2)$ \\
\hline Abnormal renal function test & $109(41.9)$ \\
\hline No idea & $39(15.0)$ \\
\hline
\end{tabular}

LSD: Lysosomal storage disorders

\section{Results}

\section{Demographics}

A total of 261 primary care physicians [109 females (41.8\%), mean age $40.1 \pm 8.8$ years, median $=40.0(32.0-47.0)$ years] were enrolled in the study. Ninety-three (35.6\%) physicians, 87 (33.3\%) physicians and 81 (31.1\%) physicians contributed from the western, middle and eastern parts of Turkey respectively. The mean working years as primary care physicians was $14.9 \pm 8.6$ years [median $=15.0(7.0-22.0)$ years]. Among the participants, 236 (90.8\%) and 197 (75.8\%) stated that they had not worked at any metabolic disease center previously and that they had never encountered any patients diagnosed with LSD before, respectively.

\section{Knowledge About LSDs}

Among the participants, $87.3 \%$ and $37.3 \%$ thought that parental consanguinity is a risk factor for LSD and that Turkey is one of the countries where LSDs are frequently seen, respectively. One hundred and forty (55.4\%) of them suggested that the symptoms and findings of LSDs are evident at birth. A total of $26.2 \%$ of the participants stated that LSD is screened during the neonatal screening program in Turkey. Another $16.5 \%$ of them had no idea about the neonatal screening program for LSD in Turkey. In their practice, 231 (88.8\%) physicians had never considered LSDs as a differential diagnosis for any patient. Participants were asked to write down the three most commonly known LSDs in the survey. Gaucher's disease, Niemann Pick disease and mucopolysaccharidosis were the most commonly known LSDs.

The mean "total knowledge score" of the physicians was $13.47 \pm 5.85$ points [median=15.0 (10.5-18.0)]. Six (2.3\%) primary care physicians had a total score of " 0 ". Only 1 of them scored "25" points (Table III). There was no correlation between scores and the primary physicians' ages, working years and geographic area where they work. When common clinical findings were listed, $15.0 \%$ of the participants stated that they had no idea about the clinical findings and symptoms of LSD (Table II). Most of the

\begin{tabular}{|l|l|}
\hline \multicolumn{2}{|l|}{ Table III. Total knowledge scores of primary care physicians } \\
\hline Score & Participants (n, \%) \\
\hline $0-5$ & $36(13.7)$ \\
\hline $6-10$ & $29(11.1)$ \\
\hline $11-15$ & $83(31.8)$ \\
\hline $16-20$ & $86(32.9)$ \\
\hline $21-25$ & $27(10.3)$ \\
\hline
\end{tabular}


participants selected growth and developmental delay, mental retardation and coarse facies as findings of LSD patients. The lowest level of knowledge was observed with cardiomyopathy, seizure and renal abnormalities (Table II). In the last part of this section, participants were asked to make a differential diagnosis for a hypothetical patient with a lysosomal storage disorder. The patient was described as a 16-year-old male with recurrent epistaxis and $10 \mathrm{~cm}$ of splenomegaly, together with laboratory investigations showing leukopenia and thrombocytopenia. Bone marrow aspiration of the patient revealed foamy cells and no atypical cells. Based on this information, 60 (23.0\%) of the 261 primary care practitioners considered Gaucher's disease for the differential diagnosis.

\section{Primary Care Physicians' Sources of their Knowledge on LSDs and Reasons of İnsufficient Knowledge}

Physicians were asked about the main source of their LSD knowledge. A total of 130 physicians (49.8\%) stated that they had gained their information about LSDs during their undergraduate education at medical school. On the other hand, $36.4 \%$ of physicians declared that they had gained their knowledge on LSDs during their studies for the [Medical Specialty Selection Examination (TUS)], which is conducted after undergraduate medical education in Turkey. Thirteen participants (5.0\%) stated that they had obtained their knowledge from academic meetings or papers. Of note, 23 physicians (8.8\%) declared that they had no idea about LSDs.

The most commonly specified reasons of insufficient knowledge on LSDs were forgetting relevant information due to the rarity of these disorders, insufficient undergraduate medical education, inadequate attention to LSDs in congress and a lack of papers on this subject published in Turkish (Table IV).

\section{Discussion}

The most important finding of this study is the fact that awareness and knowledge level of primary

Table IV. Reasons of insufficient knowledge about LSDs declared by primary care physicians

\begin{tabular}{|l|l|}
\hline Reasons & $\mathbf{n ~ ( \% )}$ \\
\hline $\begin{array}{l}\text { Forgetting knowledge due to the rarity of these } \\
\text { diseases }\end{array}$ & $229(88.4)$ \\
\hline Insufficient undergraduate medical education & $116(44.8)$ \\
\hline Inadequate attention to LSDs in congress & $61(23.6)$ \\
\hline Insufficient literature on LSDs published in Turkish & $19(7.3)$ \\
\hline
\end{tabular}

LSD: Lysergic acid diethylamide care physicians on LSDs is not satisfactorily sufficient, and undergraduate medical education about LSDs is inadequate. In this study, nearly $90 \%$ of the participants had never considered LSDs as a differential diagnosis for any of their patients before. We conducted a scoring system consisting of 15 questions about LSDs for the objective evaluation of participants. In this survey, the mean score was $13.47 \pm 5.85$ points. Six primary care physicians had a score of " 0 " and only one physician achieved the maximum score of 25 points. We described a hypothetical patient with Gaucher's disease and only one quarter of physicians established the correct diagnosis. In one study, Bulbul et al. (4) evaluated the awareness of Fabry disease in physicians who were working in the city of Kırıkkale. Consistent with our study results, they determined that only $22 \%$ of physicians considered Fabry disease in patients with clinical findings of Fabry disease as a differential diagnosis (4).

Since many patients with LSD present their symptoms first to a primary care physician, these doctors have a crucial role in the diagnosis of LSDs, in making appropriate referrals and coordinating other care support (5). People with rare diseases like LSDs are often referred from one specialist to another, with a list of symptoms and subsequent treatment failures. The National Commission on Orphan Diseases reported that 30\% of patients suffering from a rare disease end up waiting up to 5 years to receive a correct diagnosis, $15 \%$ take 6 years or more for the correct identification, and 50\% reported receiving a correct diagnosis within 1 year of visiting a physician (6). Also, Kishnani et al. (7) revealed that the diagnostic delay was up to 12.6 years for Pompe disease as per the Pompe Registry. Obtaining a detailed family history, carefully documenting the symptoms and signs of presentation, and making an early referral to specialist services would help decrease diagnostic delays and allow earlier intervention (8).

One of the most striking results of this study was the answers about the neonatal period and newborn screening programs. In recent years, one of the most common investigated issues has been newborn screening in LSDs due to the advantages in treatment for some LSDs with ERT, SRT, and HSCT (9-11). LSDs are typically not evident at birth and they are commonly progressive in nature. Both ERT and HSCT are more effective when initiated early during the course of the disease, advocating for newborn screening for these LSDs. There has been a nationwide newborn screening program in place in Turkey since 2007 for phenylketonuria, biotinidase deficiency and 
congenital hypothyroidism. Finally, in 2015 cystic fibrosis was added to the newborn screening program. In this study however, $26.2 \%$ of primary care physicians stated that LSDs are screened during the neonatal screening program in Turkey, while in fact none of the LSDs have been included in screening yet in our country. Moreover, more than half of primary care physicians suggested that symptoms and findings of LSDs occur at birth. In general, newborn screening is done for disorders which are asymptomatic in the neonatal period, at least during the early postnatal days. Therefore, the relevant explanations were contradictory.

Consistent with the literature, most of the primary care physicians associated their lack of knowledge and awareness on LSDs with insufficient undergraduate medical education and inadequate attention to LSD in congress. Poor rotation at metabolic disease departments and having seen no LSD patients before, as observed in our study, may be explained by insufficient undergraduate medical education. Furthermore, high rates of acquiring knowledge on LSDs during the studies for the TUS among primary care physicians highlights the problems of undergraduate medical educational in Turkey. It is generally unrealistic to expect a rare disease diagnosis to be made during an initial primary care consultation. However, many patients with rare diseases will present their symptoms first to a primary care physician. In terms of reducing the diagnostic gap, all primary care physicians play a crucial role in making appropriate referrals and this is possible only with education. Therefore, the role of undergraduate medical education is essential in providing a good foundation for the future doctors involved in this field $(12,13)$. Raising awareness on the burden of LSDs is possible with increased knowledge regarding the epidemiology and impacts of LSDs as well as by providing educational resources and networking opportunities for primary care physicians $(8,14,15)$.

\section{Conclusion}

Knowledge and awareness of primary care physicians on LSDs are not satisfactory in Turkey. However, the relatively low number of participants may be a limitation of our study, and further studies involving a greater number of primary care physicians are warranted to confirm our results. On the other hand, to the best of our knowledge, this is the first study performed to date to investigate the awareness and knowledge status of primary care physicians regarding LSDs. Undergraduate and postgraduate medical training play the key role to increase knowledge, thereby to reduce diagnostic delays and ultimately to improve health outcomes and quality of life for patients. Improved communication between metabolic clinics and primary care physicians, combined with continuing medical education programs may be useful tools to improve the diagnosis of these rare diseases and appropriate patient management.

\section{Ethic}

Ethics Committee Approval: The study was approved by the Ethics Committee of Dokuz Eylül University Hospital (approval number: 2016/03-14).

Informed Consent: No consent was obtained.

Peer-review: Externally peer-reviewed.

\section{Authorship Contributions}

Concept: N.A., E.K., S.B., Design: N.A., E.K., S.B., Data Collection or Processing: E.K., Analysis or Interpretation: N.A., E.K., Literature Search: E.K., Writing: E.K..

Conflict of Interest: No conflict of interest was declared by the authors.

Financial Disclosure: The authors declared that this study received no financial support.

\section{References}

1. Heese BA. Current strategies in the management of lysosomal storage diseases. Semin Pediatr Neurol 2008;15:119-26.

2. Meikle PJ, Hopwood IJ, Clague AE, Carey WF. Prevalence of lysosomal storage disorders. JAMA 1999;281:249-54.

3. Peters C, Steward CG; National Marrow Donor Program; International Bone Marrow Transplant Registry; Working Party on Inborn Errors, European Bone Marrow Transplant Group. Hematopoietic cell transplantation for inherited metabolic diseases: an overview of outcomes and practice guidelines. Bone Marrow Transplant 2003;31:229-39.

4. Bulbul FS, Dursun O, Dursun ZE. Kırıkkale'de Çalışan Hekimlerin Fabry Hastalığı ve Kalıtsal Metabolizma Hastalıkları Konusunda Farkındalık Durumu. J LSD 2012;4:1-8.

5. Elliott E, Zurynski Y. Rare diseases are a 'common' problem for clinicians. Aust Fam Physician 2015;44:630-3.

6. Groft SC. Rare diseases: identifying needs. Report of the National Commission on Orphan Diseases. Am Pharm 1990;30:33-40.

7. Kishnani PS, Amartino HM, Lindberg C, et al. Pompe Registry Boards of Advisors. Timing of diagnosis of patients with Pompe disease: data from the Pompe registry. Am J Med Genet A 2013;161:2431-43.

8. Knight AW, Senior TP. The common problem of rare disease in general practice. Med ) Aust 2006;185:82-3.

9. Lisi EC, Gillespie S, Laney D, Ali N. Patients' perspectives on newborn screening for later onset lysosomal storage diseases. Mol Genet Metab 2016;119:109-14. 
10. Matern D, Oglesbee D, Tortorelli S. Newborn screening for lysosomal storage disorders and other neuronopathic conditions. Dev Disabil Res Rev 2013;17:247-53.

11. Meikle PJ, Grasby DJ, Dean C), et al. Newborn screening for lysosomal storage disorders. Mol Genet Metab 2006;88:307-14.

12. Phillips WR. Zebras on the common: rare conditions in family practice. J Am Board Fam Pract 2004;17:283-6.
13. MacIntyre FL. One in a million: when extraordinary cases occur in an ordinary practice. J Fam Pract 1993;36:17-8.

14. Kirby T. Australia makes up for lost time on rare diseases. Lancet 2012;379:1689-90.

15. Zurynski Y, Frith K, Leonard H, Elliott E. Rare childhood diseases: How should we respond? Arch Dis Child 2008;93:1071-4. 